www.jmscr.igmpublication.org

Impact Factor 3.79

Index Copernicus Value: 5.88

ISSN (e)-2347-176x ISSN (p) 2455-0450

crossref DOI: _http://dx.doi.org/10.18535/jmscr/v4i02.45

Journal Of Medical Science And Clinical Research

\title{
Combined Mammographic and Sonographic Evaluation of Palpable Breast Masses in Correlation With Histopathological Examination
}

\author{
Authors \\ Dr Sindhu $\mathbf{N}^{1}$, Dr Srinivasa Babu $C \mathbf{R}^{2}$, Dr Pravin G $\mathbf{U}^{3}$ \\ Department of Radio-Diagnosis, Rajarajeswari Medical College and Hospital, Kambipura, Mysore Road, \\ Bangalore, Karnataka - 560074 \\ Corresponding Author \\ Dr Sindhu N \\ Assistant Professor, Department Of Radio-Diagnosis, Rajarajeswari Medical College and Hospital, \\ Kambipura, Mysore Road, Bangalore, Karnataka - 560074 \\ Email: dr.sindhu02@gmail.com,09916399144
}

\begin{abstract}
Aim \& Objectives: To evaluate the role of combined mammographic and sonographic imaging in patients with palpable masses of the breast. To correlate these findings with histopathological diagnosis (FNAC/ Biopsy). To provide systematic and practical approach to image evaluation of palpable breast masses and then evaluate its image characteristics which help in decision making by clinician as to go for biopsy or lesion follow up.

Materials and Methods: 40 patients aged 30 or above with palpable abnormalities of breast underwent combined mammographic and sonographic evaluation.

Results: 18 patients (45\%) of the palpable abnormalities had benign result and 8 patients (20\%) had malignant result. Imaging evaluation resulted in 14 (35\%) patients as suspicious cases. All lesions categorized as suspicious underwent biopsy, among them 12 resulted in malignancy and 2 benign findings. The sensitivity and specificity of combined evaluation is $85.7 \%$ and $100 \%$ respectively. The positive predictive value and negative predictive value are $100 \%$ and $86.4 \%$ respectively. In this evaluation, NPV was $86.4 \%$, a negative test result provides reassurance that the patient is unlikely to have cancer.

Conclusion: Combined mammography and sonography is appropriate to characterize the palpable breast lesion and avoids unnecessary interventions in which imaging findings are unequivocally benign. Negative findings on combined mammographic and sonographic imaging have very high specificity and are reassuring to the patient.
\end{abstract}

Keywords: Biopsy; breast; mammography; palpable lumps; sonography. 


\section{INTRODUCTION}

Breast cancer is the leading cause of nonpreventable cancer deaths among women. Great strides in early detection and improved treatment have decreased breast cancer related deaths.

Breast disorder is a common clinical problem routinely encountered in out- patient departments. Most of the so-called lesions are of benign in nature, commonly seen at puberty, lactation, middle aged and elderly women. Majority of patients present with symptoms such as breast lump, pain and discharge from the nipple. Complaints related to breast generate anxiety to the patient. It is necessary to confirm the nature of the lesion at the earliest and suitable diagnostic work up, not only to treat the lesion but also to decrease the anxiety of the patient.

Mammography is still the only proven screening method for the breast as of date and is the only one imaging technique that has a significant impact on screening asymptomatic individuals for cancer and in diagnosis, staging and patient follow up $^{1}$.

The role of ultrasonography in breast imaging has evolved over the years. In most of the clinical practice, the use of breast ultrasonography has been restricted to differentiation of cysts versus solid masses. Today ultrasonography also plays an important role in guiding interventional procedures such as needle aspiration, core-needle biopsy and pre-biopsy needle localization. It is useful in the evaluation of palpable masses not visible in radiographically dense breast, abscesses, masses that are not completely evaluable with mammography, in evaluation of pregnant and lactating mothers and in young patients susceptible to radiation damage.

The combined mammography and ultrasonography has higher sensitivity rate than the sensitivity rate observed for either modality when performed all alone ${ }^{2}$. A prompt and accurate diagnosis is essential to minimize morbidity and mortality associated with breast masses, hence we decided in this study to correlate mammographic and sonographic findings as to arrive at accurate diagnosis

\section{MATERIALS AND METHODS}

This is a prospective study conducted in 40 patients of 40 years or above with palpable abnormalities of breast who underwent combined mammographic and sonographic evaluation in the department of Radio-diagnosis.

All patients underwent diagnostic mammography, which included cranio-caudal and medio-lateral oblique views. Later all the patients were subjected to sonography of breast.

Mammography: Film Screen grid mammography of breast was carried out prior to USG evaluation with ALLENGERS MAM-VENUS with KV range between 22-35 KvP and $400 \mathrm{mAs}$. A Molybdenum target tube in conjugation with 0.3 $\mathrm{mm}$ Molybdenum filter is used. Plastic compression plates were used. Two basic views were taken, the craino-caudal and $45^{\circ}$ Mediolateral oblique view. The cassette used for Mammography was Kodak MIN-R with single sided screen with ultra sensitive films with emulsion coated on a single side of size $8 \times 10$ ".

USG: Breast sonography was carried out with PHILIPS HD 11XE, PHILIPS HD 7 with linear transducer of frequency 7-10 MHZ was used to obtain images in various planes.

Evaluation of radiographic characteristic of mass was carried out using BI-RADS criteria and nature of mass was evaluated with USG assessment. Ultrasound machine with colour Doppler was used to determine the following sonographic findings under the following headings:

Location-Superior / inferior / medial / lateral quadrant, Margins - Regular / Irregular, Width / A.P diameter ratio: $>1.4 /<1.4$, Echo texture: Homogeneous / Heterogeneous, Echogenicity Hyperechoic/ Hypoechoic, Mixed echogenic / Anechoic, Posterior sound transmission: Enhancement / shadowing, Calcification, Pseudocapsule, Vascularity and Axillary lymphadenopathy 
Results of the examination were interpreted on the basis of these findings and diagnosis was proposed after considering history and physical examination. Results were given as whether the lesion is benign or malignant and has solid or cystic characteristics.

Mammography was used to determine the following findings:

Location - Upper / lower / inner / outer quadrant, Appearance: Shape- Round/ Lobular / Irregular, Margins - Circumscribed/Microlobulated/ Indistinct or ill-defined/ spiculated, Density High / Low density, Calcification, Surrounding Halo, Skin retraction / skin thickening, Architectural distortion and Axillary lymphadenopathy.

Results of the examination were interpreted on the basis of these findings and diagnosis was proposed after considering history and physical examination.

Mammographic Findings that raise the Possibility of Malignancy

Findings that should arouse suspicion- lesion with ill-defined margins, lesion with microlobulated margin, architectural Distortion, distorted parenchymal edge, density increasing over time, clustered microcalcifications and changing calcifications

Findings that support the possibility of malignancy - Asymmetric breast tissue, Asymmetric ducts, Asymmetric veins, Skin and trabecular thickening, Nipple retraction, deviation or inversion and Enlarged axillary lymph nodes

\section{STATISTICAL ANALYSIS}

Analytical Statistics like sensitivity, specificity, positive predictive value and negative predictive value are assessed.

Inclusion Criteria - Women referred to the department of Radio - Diagnosis with palpable breast masses.
Exclusion Criteria - Women below 40 years of age with palpable abnormalities of breast in whom malignancy is not suspected on preliminary examination. Patients already undergone surgery or received radiotherapy.

\section{RESULTS AND ANALYSIS}

There were 40 patients with palpable abnormalities of breast who underwent combined mammographic and sonographic evaluation. The palpable abnormalities were reported in 15 patients in the right breast and 24 patients in left breast and 1 patient in both breasts. In these 18 patients (45\%) had benign result and 8 patients (20\%) had malignant result. Imaging evaluation resulted in $14(35 \%)$ patients as suspicious cases. All lesions categorized as suspicious underwent biopsy, among them 12 resulted in malignancy and 2 benign findings.

\section{AGE DISTRIBUTION}

Most of the patients were in the age group of 4059 years. $(72.5 \%)$. The range of the ages was from $35-75$ years with a mean of 55 years.

Table 1: Age Distribution of patients

\begin{tabular}{|c|c|}
\hline $\begin{array}{l}\text { Patients age } \\
\text { group }\end{array}$ & $\begin{array}{c}\text { No. of palpable } \\
\text { abnormalities }\end{array}$ \\
\hline$<39$ & 3 \\
\hline $40-49$ & 18 \\
\hline $50-59$ & 11 \\
\hline$>60$ & 8 \\
\hline Total & 40 \\
\hline
\end{tabular}


Graph 1: Age distribution of patients

\section{Distribution of age in years}

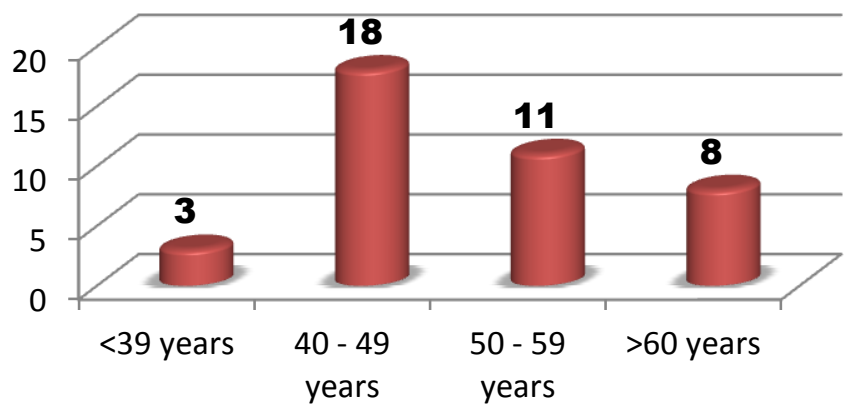

\section{DISTRIBUTION OF AFFECTED SIDE}

Graph 2: Distribution of affected side

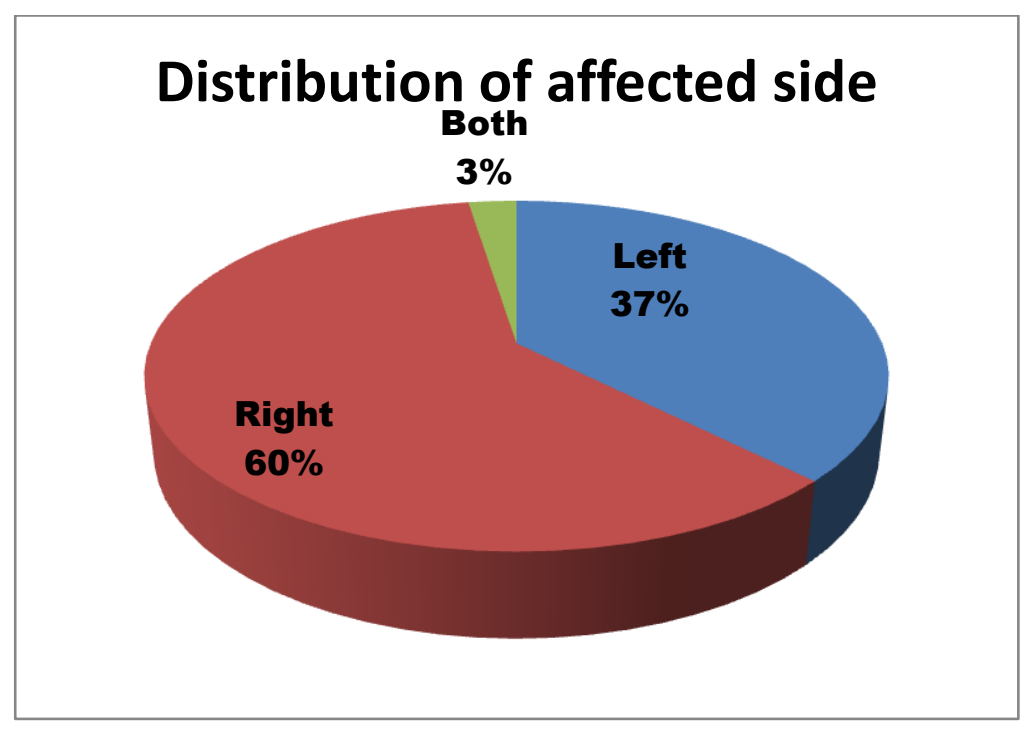

\section{LOCATION OF THE LESION:}

Most of the lesions were located in upper and outer quadrant $(47.5 \%)$

Graph 3: Location of lesions

\section{Location of Lesions}

alocation

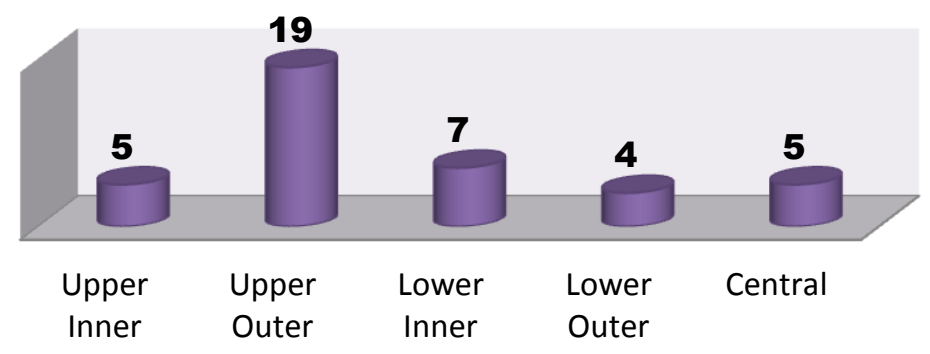


MAMMOGRAPHIC TISSUE DENSITY:

\begin{tabular}{|l|l|}
\hline Breast parenchyma density & No of patients \\
\hline N1 & 3 \\
\hline P1 & 28 \\
\hline P2 & 5 \\
\hline DY & 1 \\
\hline
\end{tabular}

Table 2: Mammographic tissue density.

Graph 4: Showing mammographic tissue densities in patients

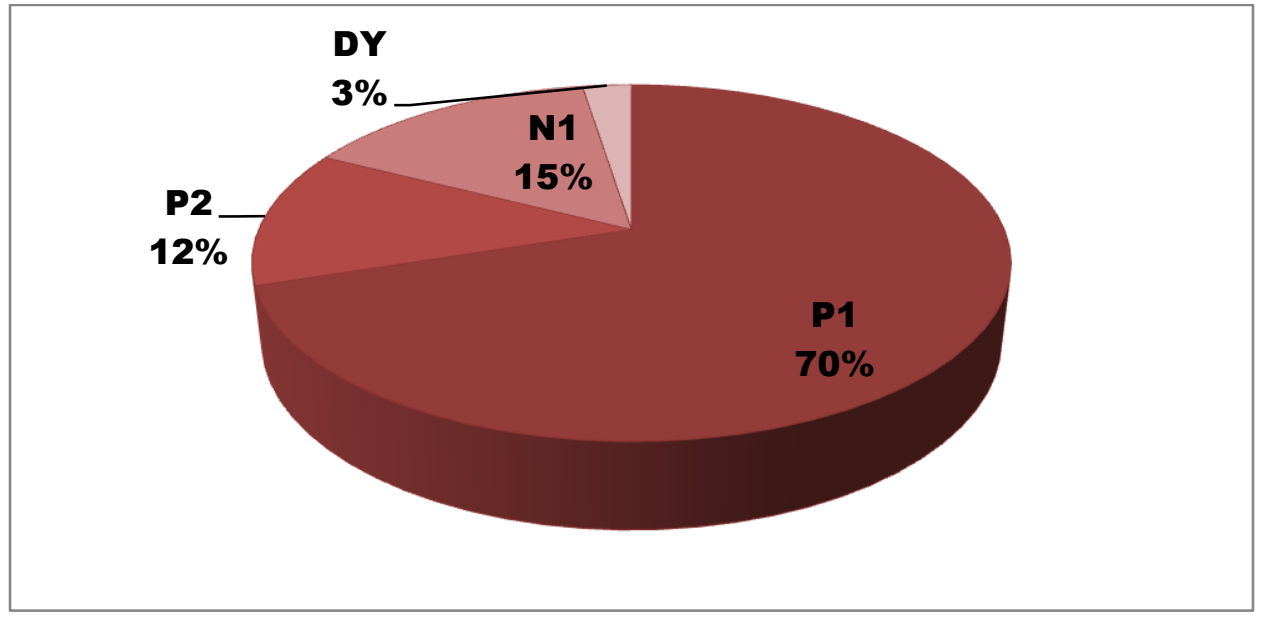

TYPES OF BENIGN LESIONS

Graph 5: Shows different types of benign lesions

\section{Types of Benign Lesion}
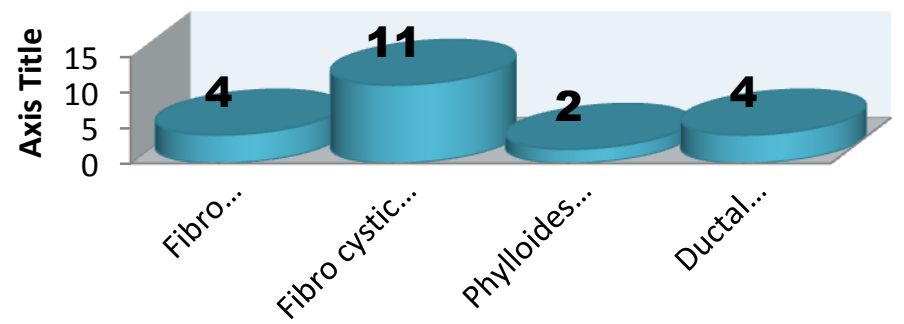

Axis Title

BENIGN AND MALIGNANT LESIONS IN DIFFERENT MAMMOGRAPHIC TISSUE DENSITIES:

Maximum number of lesions are seen in P1 breast composition. 14 benign and 14 malignant lesions. 


\section{JMSCR Vol||4||Issue||02||Page 9371-9380||February}

Table 3: No of benign and malignant lesions in different mammographic tissue densities

\begin{tabular}{|l|l|l|}
\hline $\begin{array}{c}\text { Mammographic Tissue } \\
\text { densities }\end{array}$ & Benign lesions & Malignant lesions \\
\hline N1 & 2 & 4 \\
\hline P1 & 14 & 14 \\
\hline P2 & 4 & 1 \\
\hline DY & 1 & 0 \\
\hline
\end{tabular}

Table 4: Types of benign lesions in different mammographic tissue densities

\begin{tabular}{|l|l|l|l|l|}
\hline $\begin{array}{l}\text { Mammographic } \\
\text { tissue density }\end{array}$ & $\begin{array}{l}\text { Fibrocystic } \\
\text { disease }\end{array}$ & Fibroadenoma & $\begin{array}{l}\text { Phylloides } \\
\text { tumour }\end{array}$ & $\begin{array}{l}\text { Ductal } \\
\text { proliferation }\end{array}$ \\
\hline N1 & 1 & 0 & 0 & 1 \\
\hline P1 & 7 & 3 & 2 & 2 \\
\hline P2 & 2 & 1 & 0 & 1 \\
\hline DY & 1 & 0 & 0 & 0 \\
\hline
\end{tabular}

FINAL ASSESSMENT AFTER COMBINED MAMMOGRAPHIC AND SONOGRAPHIC EVALUATION

Table 5: Final assessment after combined mammographic and sonographic evaluation

\begin{tabular}{|l|c|}
\hline Imaging findings & No of palpable abnormalities \\
\hline Benign & 18 \\
\hline Malignant & 8 \\
\hline Suspicious & 14 \\
\hline
\end{tabular}

Graph 6: Shows Combined mammographic and sonographic evaluation of palpable breast abnormalities.

\section{Combined Mammographic and Sonographic evaluation}

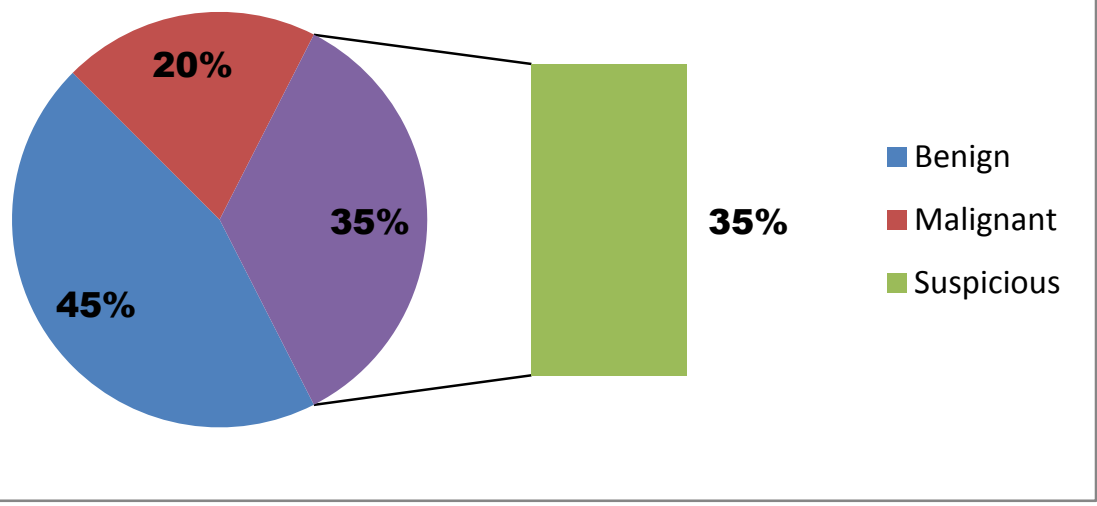




\section{TEST CHARACTERISTICS FOR COMBINED MAMMOGRAPHIC AND SONOGRAPHIC EVALUATION:}

The sensitivity and specificity of combined evaluation is $85.7 \%$ and $100 \%$ respectively. The positive predictive value and negative predictive value are $100 \%$ and $86.4 \%$ respectively.

In this evaluation, NPV is $86.4 \%$, a negative test result provides reassurance that the patient is unlikely to have cancer

Table 6: Test characteristics for combined mammographic and sonographic evaluation

\begin{tabular}{|l|l|}
\hline CHARACTERISTICS & VALUES \\
\hline Sensitivity & $85.7 \%$ \\
\hline Specificity & $100 \%$ \\
\hline Positive predictive value & $100 \%$ \\
\hline Negative predictive value & $86.4 \%$ \\
\hline
\end{tabular}

\section{DISCUSSION}

Mammography is considered the gold standard in the evaluation of the breast masses. Though various new techniques and methods have emerged, none have substituted mammography. It is still the only proven screening method for the breast as of date and is the only one imaging technique that has a significant impact on screening asymptomatic individuals for cancer diagnosis, staging and patient follow up ${ }^{1}$

The combined mammography and ultrasonography is said to have higher sensitivity rate than the sensitivity rate observed for either modality when performed all alone ${ }^{2}$.

Because of the low sensitivity of the mammography in younger women due to dense breast tissue and also low incidence of breast carcinoma in women less than $30 \mathrm{yrs}{ }^{3}$. We have included women who are 30 years or above with palpable abnormalities of breast.

Breast carcinoma has been reported in only $4 \%$ of the patients with breast symptoms and even among palpable lesions undergoing biopsy, a large number of lesions turned out to be benign ${ }^{4,5}$. The role of mammography in patients with palpable breast lumps is to show a benign cause for palpable abnormality and to avoid further intervention, to support earlier intervention for a mass with malignant features, to screen rest of the ipsilateral and contralateral breast for additional lesions and to assess the extent of malignancy when cancer is diagnosed.

However the false negative rate of mammography for breast cancer in patients with palpable abnormalities of the breasts has being reported to be as high as $16.5 \%{ }^{6}$.Multiple studies have shown that the false negative rate for combined mammographic and sonographic evaluation varies from $0 \%$ to $2.6 \%{ }^{7,8}$.Additional imaging with sonography is appropriate in most instances, with the exception of lesions that are highly indicative of malignancy, in which sonographic imaging would not add any additional information. Sonography may obviate the need for intervention by showing benign causes of palpable abnormalities such as cysts, benign intramammary lymphnodes, extravasated silicone and superficial thrombophlebitis of Mondor disease of the breast. Our study comprised of 40 patients aged 30 or above referred with brief clinical history, physical examination and provisional clinical diagnosis. All the patients were examined Sonographically and mammographically, the results were analyzed using various sonological, mammography parameters and the findings were subsequently correlated with FNAC and or biopsy confirmation. In this study, $18(45 \%)$ of the 40 lesions were categorized as benign after a combined mammographic and sonographic evaluation, clearly showing the value of imaging in helping avoiding unnecessary biopsies. 14 of the 40 patients showed suspicious features on combined imaging requiring biopsy, among them 12 resulted in malignancy and 2 had benign findings. 8 of 40 patients showed malignancy, 1 patient had ductal carcinoma with pagets disease of nipple in same breast rest all had ductal carcinoma.

Number of benign and malignant lesions in different mammographic tissue densities was 
evaluated. Maximum lesions are seen in P1 type showing 14 malignant lesions and 14 benign lesions, N1 type shows 4 malignant and 2 benign lesions, P2 type shows 1 malignant and 4 benign lesions and DY type shows only 1 benign lesions.

Morris KT et al, 2002 , [9] have stated that the best clinical approach to the diagnosis and management of patients with a breast lesion is the combination of all three tests- physical examination, radiographic imaging and pathology (Biopsy / FNAC). This diagnostic triad is called TRIPLE TEST. Diagnostic accuracy with the combination of these three tests approaches to $100 \%{ }^{10}$.

In 18 cases of benign lesions, 6 lesions were diagnosed as benign solid lesions on mammography and rest of the lesions were diagnosed as cystic in nature on ultrasonography.

We encountered 4 cases of fibroadenomas. In our study USG was more sensitive compared to mammography in diagnosing fibroadenomas. In their series Lister D et al, $1998{ }^{11}$,concluded USG is superior to mammography in diagnosing clinically benign palpable lesions. USG showed $97 \%$ accuracy compared to $87 \%$ accuracy of Mammography in clinically palpable lesions.

In our series, $18(45 \%)$ of 40 lesions were categorized as benign after a combined mammographic and sonographic evaluation, clearly showing the value of imaging in helping avoid unnecessary biopsies. Sonography is also able to characterize palpable lesions obscured by dense tissue on mammograms. Moss et al ${ }^{12}$ reported that sonography increased cancer detection by $14 \%$ in symptomatic patients who were evaluated with both mammography and sonography.

Kolb TM et al, $1998^{13}$, have studied 3626 women with dense breasts, normal mammograms. They found 11 cancers with screening US in women with dense breasts, use of screening US as a supplement to mammography resulted in increased cancer detection by $17 \%$. They concluded that US plays an important role in the detection of mammographically and clinically occult carcinoma in dense breasts.

Sonography therefore is complementary to mammography in patients with palpable abnormalities; its superiority over mammography is in being able to show lesions obscured by dense breast tissue and in characterizing palpable lesions that are mammographically visible or occult. Mammography is complementary to sonography because of its ability to screen the remainder of the ipsilateral and contralateral breast for clinically occult lesions. It has been reported that the accuracy of sonography is comparable with that of mammography as a screening modality for breast cancer.

The value of combined mammographic and sonographic imaging in symptomatic patients has been studied previously. Moss et al reported sensitivity of $94.2 \%$ and specificity of $67.9 \%$ in $368 \%{ }^{12}$. Shetty MK and shah YP reported a sensitivity of $100 \%$ and specificity of $80.1 \%{ }^{14}$. Barlow et al reported a sensitivity of $87 \%$,a specificity of $88 \%$ and positive predictive value of $22 \%{ }^{15}$.

Their findings are comparable with present findings of sensitivity of $85.7 \%$, specificity of $100 \%$, positive predictive value of $100 \%$ and negative predictive value of $86.4 \%$ in patients with palpable breast lumps.

\section{SUMMARY}

This study was undertaken to evaluate the role of mammography and sonography in characterizing the palpable breast masses.

- The study includes 40 patients with palpable breast abnormalities.

- Out of 40 patients, $18(45 \%)$ patients had benign characters in both mammography and sonography.

- 14 patients had suspicious findings on combined evaluation and biopsy was advised and of these 12 patients showed malignancy and 2 showed benign findings.

- $8(20 \%)$ patients of 40 showed malignancy in this study. 
- The positive predictive value of combined sonographic and sonographic evaluation was $100 \%$ and negative predictive value was $86.4 \%$.

\section{CONCLUSION}

Combined mammography and sonography plays an important role in the management of palpable breast lesions. Combined mammography and sonography is appropriate to

- Characterizes the palpable breast lesion.

- Avoids unnecessary interventions in which imaging findings are unequivocally benign.

- Negative findings on combined mammographic and sonographic imaging have very high specificity and are reassuring to the patient.

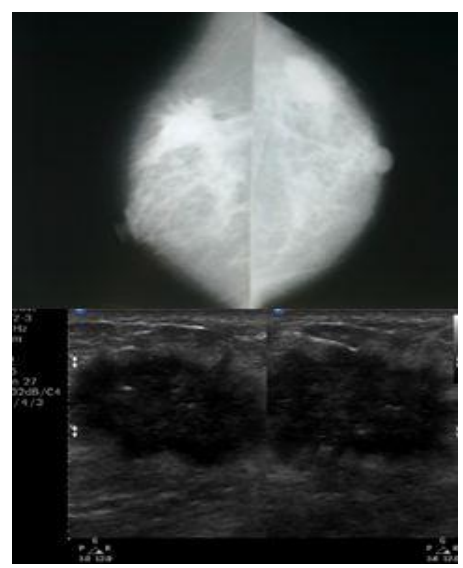

Figure 1: Conventional Mammogram and Ultrasonography image showing microlobulated mass with spiculations

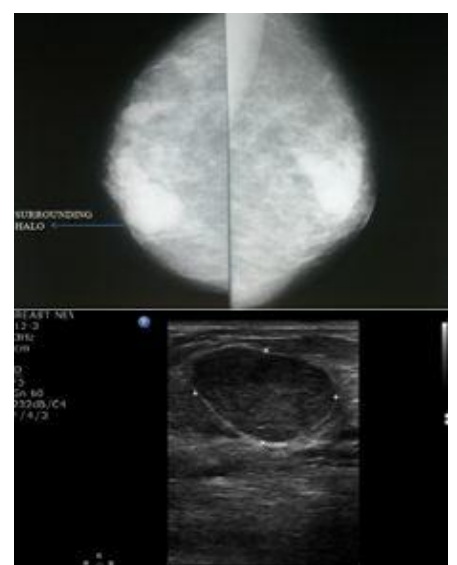

Figure 2: Conventional Mammogram and ultrasonography image showing Fibroadenoma

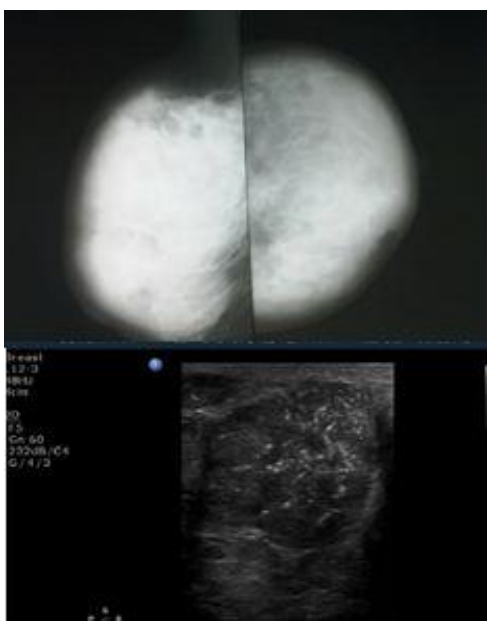

Figure 3: Conventional Mammogram and ultrasonography image shows mass with microcalcifications

\section{REFERENCES}

1. Prasad SN, Houserkova D, A comparison of mammography and ultrasonography in the evaluation of breast masses. Biomed Pap Med Fac Univ Palacky Olomouc Czech Repub. 2007 Dec; 151(2):315-22.

2. Prasad SN, The role of various modalities in breast imaging. Biomed Pap Med Fac Univ Palacky Olomouc Czech Repub.2007 Dec; 151(2):209-18

3. Bennett IC, Freitas R Jr, Fentiman IS :Diagnosis of breast cancer in young women.Avst NZJ Surg61:284-289,1991

4. Barton MB ,Elmore JG ,Fletcher SW .Breast symptoms among women enrolled in a health maintainaence organisation.Frequency,evaluation and outcome.Ann intern Med 1999 Apr 20; 130 (8):651-657

5. Perdue P,page $D$, Nellestein m,salem C,Galbo c,ghosh B.Early detection of breast carcinoma ;a comparision of palpable and non palpable lesions : Surgery 1992;111(6):656-659

6. Conveys EC, Geraghty JG ,O 'Laoide R,Hourihane IB,O'Higgins NJ .Reasons underlying negative mammography in patients with palpable breast cancer .clin.radiology1994:49(2):123-125 
7. Soo MS, Rosen EI, Baker JA, Vo TT, Boyd BA .Negative predictive value of sonography with mammography in patients with palpable breast lesions.AJR AmJ Roentgenol 2001;177;1167 -1170

8. Moy L,slantez PJ, Moore R et al .Specificity of mammography and US in the evaluation of a palpable abnormality 2002:225:176-181

9. Morris KT, Vetto JT, Petty JK, Lum SS, Schmidt WA, Toth-Fejel S and colleagues. A new score for the evaluation of palpable breast masses in women under age 40. American journal of surgery 2002; 184:245-7

10. Ahmed I, Nazir R, Chaudhary MY, Kundi $\mathrm{S}$, Triple assessment of breast lump. J Coll Physicians Surg Pak. 2007 Sep;17(9):5358

11. Lister D, Evans AJ, Burrell HC, Blamey RW, Wilson AR, Pinder SE, and collegues. The accuracy of breast ultrasound in the evaluation of clinically benign discrete, symptomatic breast lumps. Clin Radiol 1998; 53:490-2.

12. Moss HA, Britton PD, Flower CDR, Freeman AH, Lomas DJ, Warren RML. How reliable is modern breast imaging in differentiating benign from malignant breast lesions in the symptomatic population? Clin Radiol 1999; 54(10):676-682.

13. Kolb TM, Lichy J, Newhouse JH. Comparison of the performance of screening mammography, physical examination, and breast US and evaluation of factors that influence them: an analysis of 27,825 patient evaluations. Radiology 2002; 225:165-175.

14. Shetty MK \& Shah YP, Sharman RS. Prospective evaluation of value of combined mammographic and sonographic assessment in patients with palpable abnormalities of breast. J. Ultrasound Med 2003:22;263-268.
15. Barlow WE, Lehman CD, Zheng Y, et al. Performance of diagnostic mammography for women with signs or symptoms of breast cancer. J Natl Cancer Inst 2002; 94:1151-9. 